\title{
EXISTENCE AND UNIQUENESS OF SOLUTIONS FOR A DEGENERATE QUASILINEAR PARABOLIC PROBLEM
}

\author{
MAURIZIO BADII
}

\begin{abstract}
We consider the following quasilinear parabolic equation of degenerate type with convection term $u_{t}=\varphi(u)_{x x}+b(u)_{x}$ in $(-L, 0) \times$ $(0, T)$. We solve the associate initial-boundary data problem, with nonlinear flux conditions. This problem, describes the evaporation of an incompressible fluid from a homogeneous porous media. The nonlinear condition in $x=0$, means that the flow of fluid leaving the porous media depends on variable meteorological conditions and in a nonlinear manner on $u$. In $x=-L$, we have an impervious boundary. For a sufficiently smooth initial data, one proves the existence and uniqueness of the global strong solution in the class of bounded variation functions.
\end{abstract}

\section{Introduction}

In this paper we study the existence and uniqueness of solutions for the following degenerate quasilinear parabolic problem
(1) $u_{t}=\varphi(u)_{x x}+b(u)_{x}$,
in $(-L, 0) \times(0, T)$
(2) $\varphi(u(0, t))_{x}+b(u(0, t))=-\nu(u(0, t)) q(t)$, for $t \in(0, T)$
(3) $\varphi(u(-L, t))_{x}+b(u(-L, t))=0$,
for $t \in(0, T)$
(4) $u(x, 0)=u_{0}(x)$, in $(-L, 0)$.

Partially supported by G.N.A.F.A.-C.N.R. and M.U.R.S.T. $40 \%$. 
Throughout the remainder of the paper we shall assume that the following hypothesis are satisfied

$\left(H_{\varphi}\right)\left\{\begin{array}{l}\varphi \in C^{1}([0,1]), \varphi(0)=\varphi^{\prime}(0)=0 \text { and } \varphi^{\prime}(s)>0 \text { for } s>0 \text { and } \\ \varphi^{-1} \text { is Hölder continuous of order } \theta \in(0,1) ;\end{array}\right.$

$\left(H_{b}\right) b \in C^{0,1}([0,1]), b(0)=0$ and $|b(s)| \leq \rho|s| ;$

$\left(H_{\nu}\right)\left\{\begin{array}{l}\nu:[0,1] \rightarrow[0,1] \text { is continuous, increasing with } \\ \nu(0)=0 \text { and } \nu(1)=1 ;\end{array}\right.$

$\left(H_{q}\right) \forall t \in[0, T], q(t) \geq 0$ is continuous and nonincreasing;

$\left(H_{0}\right) u_{0} \in H^{1}(-L, 0), 0 \leq u_{0}(x) \leq 1, \forall x \in[-L, 0]$.

Problem (1)-(4) describes the evaporation of a homogeneous, incompressible fluid from a homogeneous, isotropic and rigid soil, with variable meteorological conditions. In $x=0$ the nonlinear condition of FourierRobin means that the flow of water leaving the soil, vanishes for $u=0$ while assume its maximal value when $u$ is maximal. Between these values, the flow of water depends in a nonlinear manner on $u$ and with a $q(t)$ which represents variable meteorological conditions. Assumption (3) means an impervious boundary.

Equation (1) is a useful model in many different applications as, for instance, the flow of groundwater in a homogeneous, isotropic, rigid, and unsaturated porous medium. If we choose the coordinate $x$ to measure the vertical height from ground level and pointing upward, the soil is represented by the vertical column $(-L, 0)$.

If $\theta(x, t)$ denotes the moisture content, defined as the volume of water present per unit volume of soil and $v(x, t)$ is the seepage velocity of the water, the law by which fluid flows through porous media can be described, was found by Darcy experimentally and is given by

$$
v=-k(\theta) \Phi_{x}
$$

and the continuity equation

$$
\theta_{t}+v_{x}=0
$$

In (5), $k(\theta)$ is the hydraulic conductivity of soil and $\Phi$ is the total potential. When absorption and chimical osmotic and thermal effect are negligible, the total potential may be expressed as $\Phi=\psi(\theta)+x$, where $\psi(\theta)$ is the hydrostatic potential due to capillary suction. Combining both equations (5), (6), we obtain

$$
\theta_{t}=\left(k(\theta) \psi_{\theta}(\theta) \theta_{x}+k(\theta)\right)_{x}=\left(D(\theta) \theta_{x}+k(\theta)\right)_{x}
$$


where $D(\theta):=k(\theta) \psi_{\theta}(\theta)$ denotes the soil moisture diffusivity.

By defining $\varphi(s):=\int_{0}^{s} D(r) d r$ and $b(s):=k(s),(7)$ yields (1).

In problem (1)-(4), $u$ denotes the saturation of soil, for this we require the condition $u \geq 0$.

In the present paper, we prove the existence and uniqueness of solution for (1)-(4), considering at first a quasilinear parabolic problem of nondegenerate type, approximating problem (1)-(4).

This nondegenerate problem is obtained adding a so called "artificial viscosity" term, substituting $\varphi$ with $\varphi+1 / k, k \in \mathbb{N}$ in (1). The nondegenerate problem, is studied using a semi-discretization scheme in the time. One proves the existence and uniqueness of solution $u_{k}$ for the approximate problem. Existence of solution $u$ for (1)-(4) is then proved, going to the limit for $k \rightarrow \infty$. For this reason, we look for estimates which are independent of $k$. With the assumption $\varphi\left(u_{0}\right)_{x}+$ $b\left(u_{0}\right) \in B V(-L, 0)$, we prove the existence of solution $u$ for (1)-(4) in the $B V\left(0, T ; L^{1}(-L, 0)\right)$ spaces. Finally, we prove the uniqueness of solution for (1)-(4), with the further assumption that $b\left(\varphi^{-1}\right)$ is Hölder continuous of order $1 / 2$ draw our inspiration from [6] where is proved the uniqueness of a bounded variational solution for a nonlinear degenerate diffusion-convection variational inequality connected to an oil engineering problem. In [2], [11] is studied a nonlinear parabolic problem, with a nonlinear integro-differential term and with nonlinear boundary conditions. This authors, prove the uniqueness of solution in the class of $B V$ functions. We remember also [1] and [7].

Related work, although rather different, can be found in [5] and [10] and references given therein.

\section{Existence of solutions for an approximate problem}

In the following, we denote with $B V(0, T)$ the space of functions $u$ such that are locally integrable on $(0, T)$ and whose generalized derivative is an integrable measure of Radon on $(0, T)$. For more details on $B V$ spaces, see $[\mathbf{1 0}]$.

Let $V:=H^{1}(-L, 0)$ and $V^{\prime}$ its dual space, we denote with $(\cdot, \cdot)$ both the pairing of duality $V^{\prime}, V$ and the usual inner product in $L^{2}(-L, 0)$. The inner product in $V$ is defined by $(u, v)_{1}=(u, v)+\left(u_{x}, v_{x}\right)$.

By Sobolev's embedding Theorem, $V \subset C([-L, 0])$, with continuous injection.

Definition 1. For a strong solution of (1)-(4) on $(0, T)$, we mean a function $u \in B V\left(0, T ; L^{1}(-L, 0)\right) \cap L^{\infty}\left(Q_{T}\right), 0 \leq u(x, t) \leq 1$ a.a. on 
$Q_{T}:=(-L, 0) \times(0, T)$, such that $u_{t} \in L^{2}\left(0, T ; V^{\prime}\right), \varphi(u) \in H^{1}\left(Q_{T}\right) \cap$ $L^{\infty}\left(Q_{T}\right), u(x, 0)=u_{0}(x)$, a.a. on $(-L, 0)$ and

$$
\begin{aligned}
& \int_{0}^{t}\left(u_{s}, v\right) d s+\int_{0}^{t} \nu(u(0, s)) q(s) v(0, s) d s \\
+ & \int_{0}^{t} \int_{-L}^{0}\left(\varphi(u)_{x}+b(u)\right) v_{x} d x d s=0,
\end{aligned}
$$

for any $v \in L^{2}(0, T ; V)$ and for all $t \in(0, T)$.

To prove the existence of solutions for (1)-(4), we consider a semidiscretized scheme. Divide $[0, T]$ in steps of ugual length $h=\Delta t=T / N$, $N \in \mathbb{N}$ (discretization time step) so, $[0, T]=\bigcup_{n=1}^{N}[(n-1) h, n h]$.

Now, we consider an approximation of $u$ at time $n h$ defining $u^{n}(x):=$ $u(x, n h)$. Set $q^{n}:=(1 / h) \int_{(n-1) h}^{n h} q(t) d t$ and $\phi_{k}(r):=\varphi(r)+r / k, \forall k \in \mathbb{N}$. Since $\phi_{k}(\cdot)$ is an increasing function, there exists $\phi_{k}^{-1}(\cdot)$.

It is not a priori known that solution $u$ is in $[0,1]$, therefore we consider the continuations on all $\mathbb{R} \tilde{v}, \tilde{\varphi}, \tilde{b}$, respectively of $\nu, \varphi$ and $b$, defining $\tilde{\nu}(s)=\tilde{b}(s)=\tilde{\varphi}(s)=0$ for $s \leq 0$ and $\tilde{\nu}(s)=\nu(1), \tilde{b}(s)=b(1), \tilde{\varphi}(s)=$ $\varphi(1)$ for $s \geq 1$. Now, we can resolve the following

Problem $\left(P_{n}\right)$ :

Let $u_{0}$ be given such that $0 \leq u_{0}(x) \leq 1$, a.a. in $(-L, 0)$. To find $u_{k}^{n} \in V, \forall n \geq 1$ solution of the nonlinear elliptic equation

$$
\begin{aligned}
& \quad(1 / h)\left(u_{k}^{n}-u_{k}^{n-1}, v\right)+\tilde{\nu}\left(u_{k}^{n}(0)\right) q^{n} v(0)+\int_{-L}^{0} \tilde{\varphi}\left(u_{k}^{n}\right)_{x} v_{x} d x \\
& +(1 / k) \int_{-L}^{0} u_{k x}^{n} v_{x} d x+\int_{-L}^{0} \tilde{b}\left(u_{k}^{n}\right) v_{x} d x=0, \forall v \in V, n=1,2, \ldots, N-1 \\
& u_{k}^{0}=u_{0} .
\end{aligned}
$$

The solution of $\left(P_{n}\right)$ is based on the solution of the following nonlinear equation

Equation $\left(P_{s}\right)$ :

To find $z_{k} \in V$, such that

$$
\begin{aligned}
\mu\left(z_{k}, v\right)+ & \tilde{\nu}\left(z_{k}(0)\right) q^{k} v(0)+\int_{-L}^{0} \tilde{\varphi}\left(z_{k}\right)_{x} v_{x} d x+(1 / k) \int_{-L}^{0} z_{k x} v_{x} d x \\
& +\int_{-L}^{0} \tilde{b}\left(z_{k}\right) v_{x} d x=(g, v), \quad \forall v \in V, \mu \geq 0, g \in L^{2}(-L, 0) .
\end{aligned}
$$


Proposition 1. If $\left(H_{\varphi}\right),\left(H_{b}\right),\left(H_{\nu}\right)$ hold, there exists a solution $z_{k} \in$ $V$ of equation $\left(P_{s}\right)$.

Proof: The existence of solution, is proved by Schauder's fixed point Theorem.

Proposition 2. If $\left(H_{\varphi}\right),\left(H_{b}\right),\left(H_{\nu}\right)$ hold, there exists a solution $u_{k}^{n} \in$ $V$ for problem $\left(P_{n}\right)$.

Proof: Solved equation $\left(P_{s}\right)$, it is possible to resolve problem $\left(P_{n}\right)$ by recurrence with respect to $n$.

We show some properties of solutions $u_{k}^{n}$.

Proposition 3. Let $u_{0}$ be given with $0 \leq u_{0}(x) \leq 1$, a.a. in $(-L, 0)$ and $\left(H_{\varphi}\right),\left(H_{b}\right),\left(H_{\nu}\right)$ hold, then $u_{k}^{n}$ are nonnegative on $[-L, 0]$.

Proof: We proceed by recurrence. We consider

$$
\begin{aligned}
(1 / h)\left(u_{k}^{1}-u_{0}, v\right)+\tilde{\nu} & \left(u_{k}^{1}(0)\right) q^{1} v(0)+\int_{-L}^{0} \tilde{\varphi}\left(u_{k}^{1}\right)_{x} v_{x} d x \\
& +(1 / k) \int_{-L}^{0} u_{k x}^{1} v_{x} d x+\int_{-L}^{0} \tilde{b}\left(u_{k}^{1}\right) v_{x} d x=0
\end{aligned}
$$

and choose $v=\left(u_{k}^{1}\right)^{-}$, one has

$$
\begin{aligned}
& \text { (10) }(1 / h)\left(u_{k}^{1}-u_{0},\left(u_{k}^{1}\right)^{-}\right)+\tilde{\nu}\left(u_{k}^{1}(0)\right) q^{1}\left(u_{k}^{1}(0)\right)^{-} \\
& +\int_{-L}^{0} \tilde{\varphi}\left(u_{k}^{1}\right)_{x}\left(u_{k}^{1}\right)_{x}^{-} d x+(1 / k) \int_{-L}^{0} u_{k x}^{1}\left(u_{k}^{1}\right)_{x}^{-} d x+\int_{-L}^{0} \tilde{b}\left(u_{k}^{1}\right)\left(u_{k}^{1}\right)_{x}^{-} d x=0 .
\end{aligned}
$$

Now, $\tilde{\nu}\left(u_{k}^{1}(0)\right) q^{1}\left(u_{k}^{1}(0)\right)^{-} \equiv 0$, thus $(10)$ gives

$$
\begin{aligned}
-(1 / h) \int_{\left[u_{k}^{1}<0\right]}\left|u_{k}^{1}\right|^{2} d x-(1 / k) \int_{\left[u_{k}^{1}<0\right]}\left|u_{k x}^{1}\right|^{2} d x & \\
& =-(1 / h) \int_{\left[u_{k}^{1}<0\right]} u_{0} u_{k}^{1} d x
\end{aligned}
$$

that is a contradiction. Hence, $u_{k}^{1} \geq 0$ and by recurrence one proves that $u_{k}^{n} \geq 0$ in $[-L, 0]$

In the following Proposition, we use a Lipschitz increasing approximation of the function of Heaviside, which is well posed with respect to the following assumption

$$
\left|\tilde{b}\left(\tilde{\phi}_{k}^{-1}(s)\right)-\tilde{b}\left(\tilde{\phi}_{k}^{-1}(\hat{s})\right)\right| \leq c|s-\hat{s}|^{1 / 2} .
$$


Proposition 4. With assumptions $\left(H_{\varphi}\right),\left(H_{b}\right),\left(H_{\nu}\right)$ and $(12)$, problem $\left(P_{n}\right)$ has a unique solution.

Proof: It is sufficient to prove the uniqueness of $u_{k}^{1}$. Let $u_{k}^{1}, \hat{u}_{k}^{1}$ be solutions of problem $\left(P_{1}\right)$. We define

$$
s_{\varepsilon}(w)\left\{\begin{array}{lll}
=0, & & \text { if } w \leq \varepsilon<1 \\
=1-\log w / \log \varepsilon, & & \text { if } 0<\varepsilon \leq w
\end{array}\right.
$$

where $w:=\tilde{\phi}_{k}\left(u_{k}^{1}\right)-\tilde{\phi}_{k}\left(\hat{u}_{k}^{1}\right)$.

$$
\begin{gathered}
(1 / h)\left(u_{k}^{1}-\hat{u}_{k}^{1}, s_{\varepsilon}(w)\right)+\left(\tilde{\nu}\left(u_{k}^{1}(0)\right)-\tilde{\nu}\left(\hat{u}_{k}^{1}(0)\right)\right) q^{1} s_{\varepsilon}(w(0)) \\
-(1 / \log \varepsilon) \int_{[w>\varepsilon]}\left(\left|w_{x}\right|^{2} / w\right) d x \\
=(1 / \log \varepsilon) \int_{[w>\varepsilon]}\left(\left(\tilde{b}\left(u_{k}^{1}\right)-\tilde{b}\left(\hat{u}_{k}^{1}\right)\right)\left(w_{k} / w\right) d x\right. \\
\leq(-c \sqrt{L} / \log \varepsilon)\left(\int_{[w>\varepsilon]}\left(\left|w_{x}\right|^{2} / w\right) d x\right)^{1 / 2}
\end{gathered}
$$

for (12) and the inequality of Hölder.

Since, $\left(u_{k}^{1}-\hat{u}_{k}^{1}, s_{\varepsilon}(w)\right) \geq 0$ and $\left(\tilde{\nu}\left(u_{k}^{1}(0)\right)-\tilde{\nu}\left(\hat{u}_{k}^{1}(0)\right)\right) q^{1} s_{\varepsilon}(w(0)) \geq 0$ because of the monotonicity of $\nu(\cdot)$, we have

$$
\begin{aligned}
& (-1 / \log \varepsilon) \int_{[w>\varepsilon]}\left(\left|w_{x}\right|^{2} / w\right) d x \\
& \quad \leq(-c \sqrt{L} / \log \varepsilon)\left(\int_{[w>\varepsilon]}\left(\left|w_{x}\right|^{2} / w\right) d x\right)^{1 / 2}
\end{aligned}
$$

which implies

$$
\int_{[w>\varepsilon]}\left(\left|w_{x}\right|^{2} / w\right) \leq c^{2} L
$$

Going to the limit as $\varepsilon \rightarrow 0$ in (14), since $s_{\varepsilon}(w) \rightarrow \operatorname{sgn}^{+} w$ and because of (16), one has

$$
(1 / h) \int_{-L}^{0}\left(u_{k}^{1}-\hat{u}_{k}^{1}\right)^{+} d x \leq 0 .
$$

Thus, the claim holds. 
Now we specialize the choice of $u_{0}$, assuming that

$$
u_{0} \in V, \quad 0 \leq u_{0}(x) \leq 1, \forall x \in[-L, 0]: \varphi\left(u_{0}\right) \in V
$$

(18) satisfies the condition

$$
\int_{-L}^{0} \phi_{k}\left(u_{0}\right)_{x} v_{x} d x+\int_{-L}^{0} b\left(u_{0}\right) v_{x} d x \geq 0, \quad \forall v \in V
$$

with $v(x) \geq 0$ in $[-L, 0]$.

Then we obtain:

Proposition 5. If $\left(H_{\varphi}\right),\left(H_{b}\right),\left(H_{\nu}\right),(12)$ and (18) hold and $q^{i-1} \geq$ $q^{i}, i=1,2, \ldots, N-1$, then

$$
u_{k}^{n}(x) \leq u_{k}^{n-1}(x) \leq \cdots \leq u_{0}(x), \quad \forall x \in[-L, 0] .
$$

Proof: We proceed by recurrence.

$$
\begin{aligned}
(1 / h)\left(u_{k}^{1}-u_{0}, v\right)+ & \tilde{\nu}\left(u_{k}^{1}(0)\right) q^{1} v(0) \\
& +\int_{-L}^{0} \tilde{\phi}_{k}\left(u_{k}^{1}\right)_{x} v_{x} d x+\int_{-L}^{0} \tilde{b}\left(u_{k}^{1}\right) v_{x} d x=0 .
\end{aligned}
$$

Subtracting (18) by (20), we obtain for $v=s_{\varepsilon}(w), s_{\varepsilon}(w)$ as in (13), and $w:=\tilde{\phi}_{k}\left(u_{k}^{1}\right)-\tilde{\phi}_{k}\left(u_{0}\right)$

$$
\begin{aligned}
& (1 / h)\left(u_{k}^{1}-u_{0}, s_{\varepsilon}(w)\right)+\tilde{\nu}\left(u_{k}^{1}(0)\right) q^{1} s_{\varepsilon}(w(0)) \\
& -(1 / \log \varepsilon) \int_{[w>\varepsilon]}\left(\left|w_{x}\right|^{2} / w\right) d x \\
& \quad \leq(-1 / \log \varepsilon) \int_{[w>\varepsilon]}\left(\left(\tilde{b}\left(u_{0}\right)-\tilde{b}\left(u_{k}^{1}\right)\right)\left(w_{x} / w\right) d x .\right.
\end{aligned}
$$

Arguing as in Proposition 4 and going to the limit for $\varepsilon \rightarrow 0$, one has

$$
u_{k}^{1}(x) \leq u_{0}(x), \quad \forall x \in[-L, 0] .
$$

Now,

$$
\begin{aligned}
(1 / h)\left(u_{k}^{2}-u_{k}^{1}, v\right)+ & \tilde{\nu}\left(u_{k}^{2}(0)\right) q^{2} v(0) \\
& +\int_{-L}^{0} \tilde{\phi}_{k}\left(u_{k}^{2}\right)_{x} v_{x} d x+\int_{-L}^{0} \tilde{b}\left(u_{k}^{2}\right) v_{x} d x=0 .
\end{aligned}
$$


Subtracting (20) by (23), one has

$$
\begin{aligned}
& (1 / h)\left(u_{k}^{2}-u_{k}^{1}-u_{k}^{1}+u_{0}, v\right)+\left(\tilde{\nu}\left(u_{k}^{2}(0)\right) q^{2}-\tilde{\nu}\left(u_{k}^{1}(0)\right) q^{1}\right) v(0) \\
& +\int_{-L}^{0}\left(\tilde{\phi}_{k}\left(u_{k}^{2}\right)-\tilde{\phi}_{k}\left(u_{k}^{1}\right)\right)_{x} v_{x} d x+\int_{-L}^{0}\left(\tilde{b}\left(u_{k}^{2}\right)-\tilde{b}\left(u_{k}^{1}\right)\right) v_{x} d x=0 .
\end{aligned}
$$

By (22), for $v=s_{\varepsilon}(w), w:=\tilde{\phi}_{k}\left(u_{k}^{2}\right)-\tilde{\phi}_{k}\left(u_{k}^{1}\right), q^{2} \leq q^{1}$ and going to the limit as $\varepsilon \rightarrow 0$ in (24), we obtain

$$
(1 / h) \int_{-L}^{0}\left(u_{k}^{2}-u_{k}^{1}\right)^{+} d x \leq 0
$$

which implies

$$
u_{k}^{2}(x) \leq u_{k}^{1}(x), \quad \forall x \in[-L, 0] .
$$

By recurrence, (19) follows.

From $u_{k}^{n}$, we construct functions

$$
u_{h, k}(x, t):=\sum_{n=0}^{N-1} u_{k}^{n}(x) \chi^{n}(t)
$$

where $\chi^{n}(\cdot)$ is the characteristic function of $[n h,(n+1) h],\left(u_{h, k}\right.$ is a step approximation of $u_{k}$ ) and

$$
\sigma_{h, k}(x, t)\left\{\begin{aligned}
= & (t-n h)\left(\left(u_{k}^{n}(x)-u_{k}^{n-1}(x)\right) / h\right) & & t \in[n h,(n+1) h] \\
& +u_{k}^{n-1}(x), & & n=1, \ldots, N-1 \\
= & u_{0}(x), & & t \in[0, h]
\end{aligned}\right.
$$

( $\sigma_{h, k}$ is a piecewise linear approximation of $u_{k}$, continuous in $t$ ).

We can prove the following

Proposition 6. With the assumptions of Proposition 5, then $u_{h, k}$ is bounded with respect to $h$ in $L^{2}(0, T ; V) \cap L^{\infty}\left(0, T ; L^{2}(-L, 0)\right)$.

Proof: Choosing in $\left(P_{n}\right) v=u_{k}^{n}$, one has

$$
\begin{aligned}
(1 / h)\left(u_{k}^{n}-u_{k}^{n-1},\right. & \left.u_{k}^{n}\right)+\nu\left(u_{k}^{n}(0)\right) q^{n} u_{k}^{n}(0)+(1 / k)\left\|u_{k x}^{n}\right\|_{2}^{2} \\
& +\int_{-L}^{0} \varphi^{\prime}\left(u_{k}^{n}\right)\left|u_{k x}^{n}\right|^{2} d x+\int_{-L}^{0} b\left(u_{k}^{n}\right) u_{k x}^{n} d x=0
\end{aligned}
$$


since,

$$
\begin{aligned}
\left(u_{k}^{n}\right. & \left.-u_{k}^{n-1}, u_{k}^{n}\right) \\
& =(1 / 2)\left[\left(u_{k}^{n}, u_{k}^{n}\right)-\left(u_{k}^{n-1}, u_{k}^{n-1}\right)+\left(u_{k}^{n}-u_{k}^{n-1}, u_{k}^{n}-u_{k}^{n-1}\right)\right]
\end{aligned}
$$

by (29) we obtain

$$
\begin{aligned}
& (1 / 2 h)\left[\left\|u_{k}^{n}\right\|_{2}^{2}-\left\|u_{k}^{n-1}\right\|_{2}^{2}+\left\|u_{k}^{n}-u_{k}^{n-1}\right\|_{2}^{2}\right]+\nu\left(u_{k}^{n}(0)\right) q^{n} u_{k}^{n}(0) \\
& \quad+(1 / k)\left\|u_{k x}^{n}\right\|_{2}^{2}+\int_{-L}^{0} \varphi^{\prime}\left(u_{k}^{n}\right)\left|u_{k x}^{n}\right|^{2} d x+\int_{-L}^{0} b\left(u_{k}^{n}\right) u_{k x}^{n} d x=0
\end{aligned}
$$

Hence,

(32) $(1 / 2 h)\left[\left\|u_{k}^{n}\right\|_{2}^{2}-\left\|u_{k}^{n-1}\right\|_{2}^{2}\right]+(1 / k)\left\|u_{k x}^{n}\right\|_{2}^{2}+\int_{-L}^{0} b\left(u_{k}^{n}\right) u_{k x}^{n} d x \leq 0$.

By the inequality of Young and multiplying by $h$, one has

$$
\begin{aligned}
(1 / 2)\left[\left\|u_{k}^{n}\right\|_{2}^{2}\right. & \left.-\left\|u_{k}^{n-1}\right\|_{2}^{2}\right]+(h / k)\left\|u_{k x}^{n}\right\|_{2}^{2} \\
& \leq(h k / 2) \int_{-L}^{0}\left|b\left(u_{k}^{n}\right)\right|^{2} d x+(h / 2 k)\left\|u_{k x}^{n}\right\|_{2}^{2} \\
& \left.\leq\left(\rho^{2} h k / 2\right) \int_{-L}^{0}\left|u_{k}^{n}\right|^{2} d x+(h / 2 k)\left\|u_{k x}^{n}\right\|_{2}^{2} \text { (for }\left(H_{b}\right)\right) \\
& \leq\left(\rho^{2} h k / 2\right)\left\|u_{0}\right\|_{2}^{2}+(h / 2 k)\left\|u_{k x}^{n}\right\|_{2}^{2} \text { (for (19)). }
\end{aligned}
$$

Thus,

$$
\left\|u_{k}^{n}\right\|_{2}^{2}-\left\|u_{k}^{n-1}\right\|_{2}^{2}+(h / k)\left\|u_{k x}^{n}\right\|_{2}^{2} \leq h C_{k}\left\|u_{0}\right\|_{2}^{2}
$$

where

$$
C_{k}:=\rho^{2} k
$$

Adding up on $n$, we obtain

$$
\left\|u_{k}^{n}\right\|_{2}^{2}+(h / k) \sum_{s=1}^{n}\left\|u_{k x}^{s}\right\|_{2}^{2} \leq\left(T C_{k}+1\right)\left\|u_{0}\right\|_{2}^{2}, \quad(h N=T) .
$$

Hence,

$$
\left\|u_{k}^{n}\right\|_{2}^{2} \leq\left(T C_{k}+1\right)\left\|u_{0}\right\|_{2}^{2}
$$


and

$$
h \sum_{s=1}^{N-1}\left\|u_{k x}^{s}\right\|_{2}^{2} \leq k\left(\left(T C_{k}+1\right)\left\|u_{0}\right\|_{2}^{2}\right) .
$$

The (36) and (37) give

$$
\left\|u_{h, k}\right\|_{L^{2}(0, T ; V) \cap L^{\infty}\left(0, T ; L^{2}(-L, 0)\right)} \leq C_{k}^{\prime} .
$$

By (38), there exists a subsequence, that we denote again with $u_{h, k}$, such that $u_{h, k}-u_{k}$ as $h \rightarrow 0$ in $L^{2}(0, T ; V)$ and in $L^{\infty}\left(0, T ; L^{2}(-L, 0)\right)-^{*}$ weak.

Thus, $u_{k} \in L^{2}(0, T ; V) \cap L^{\infty}\left(0, T ; L^{2}(-L, 0)\right)$. Now, we consider (28). Then,

$$
\left(\sigma_{h, k}(x, t)\right)_{t} \begin{cases}=\left(u_{k}^{n}(x)-u_{k}^{n-1}(x)\right) / h, & t \in[n h,(n+1) h], \\ & n=1,2, \ldots, N-1 \\ =0, & t \in[0, h] .\end{cases}
$$

It is easy to prove that

(40) $\left\|\sigma_{h, k}\right\|_{L^{2}(0, T ; V)}^{2}$

$$
\leq T\left\|u_{0}\right\|_{H^{1}}^{2}+(7 / 3) C_{k}^{\prime} ; \quad\left\|\left(\sigma_{h, k}\right)_{t}\right\|_{L^{2}\left(Q_{\delta}\right)}^{2} \leq C_{\delta}, \forall 0<\delta<T
$$

where $Q_{\delta}:=(-L, 0) \times(\delta, T)$ and $C_{\delta}$ is independent of $h, k$; from the problem $\left(P_{n}\right)$ one has

$$
\left\|\left(\sigma_{h, k}\right)_{t}\right\|_{L^{2}\left(0, T ; V^{\prime}\right)}^{2} \leq C_{k}^{\prime} .
$$

Set

$$
W(0, T):=\left\{v \in L^{2}(0, T ; V): v_{t} \in L^{2}\left(0, T ; V^{\prime}\right)\right\}
$$

from a classic result, it is known that $W(0, T)$ is compactly embedded in $L^{2}\left(Q_{T}\right)$. Since $\sigma_{h, k}$ is in a fixed bounded set of $W(0, T)$ and holds the following estimate:

$$
\left\|\sigma_{h, k}-u_{h, k}\right\|_{L^{2}\left(Q_{T}\right)} \leq \sqrt{h}\left\|u_{0}\right\|_{L^{2}(-L, 0)},
$$

there exists a subsequence denoted by $\sigma_{\tilde{h}, k}$, such that when $\tilde{h} \rightarrow 0^{+}$

$$
\begin{aligned}
& \sigma_{\tilde{h}, k} \rightarrow u_{k} \text { in } L^{2}\left(Q_{T}\right) \text { and a.a. } \\
& u_{\tilde{h}, k} \rightarrow u_{k} \text { in } L^{2}\left(Q_{T}\right) \text { and a.a. }
\end{aligned}
$$


That is, because of (27), $u_{k}^{n} \rightarrow u_{k}$ in $L^{2}\left(Q_{T}\right)$ and a.a. as $n \rightarrow \infty$. By the Theorem of Lebesgue, $b\left(u_{k}^{n}\right) \rightarrow b\left(u_{k}\right)$ in $L^{2}\left(Q_{T}\right)$ and a.a. for $n \rightarrow \infty$. Also $\left\|\left(u_{h, k}\right)_{x}\right\|_{L^{2}\left(Q_{T}\right)} \leq C_{k}^{\prime}$ so, for a subsequence, we have that $u_{k x}^{n} \rightarrow u_{k x}$ in $L^{2}\left(Q_{T}\right)$. Therefore, $\varphi^{\prime}\left(u_{k}^{n}\right) u_{k x}^{n} \rightarrow \varphi^{\prime}\left(u_{k}\right) u_{k x}$ in $L^{2}\left(Q_{T}\right)$ as $n \rightarrow \infty$ and by (41), for a subsequence, one has that $\left(\sigma_{h, k}\right)_{t} \rightarrow u_{k t}$ in $L^{2}\left(0, T ; V^{\prime}\right)$ and in $L^{2}\left(Q_{\delta}\right), \forall \delta>0$ for $(40)$, as $h \rightarrow 0$.

Going to the limit in $\left(P_{n}\right)$ for $n \rightarrow \infty$, we obtain

(43) $\left(u_{k t}, v\right)+\nu\left(u_{k}(0, t)\right) q(t) v(0, t)+(1 / k)\left(u_{k x}, v_{x}\right)$

$+\int_{-L}^{0} \varphi\left(u_{k}\right)_{x} v_{x} d x+\int_{-L}^{0} b\left(u_{k}\right) v_{x} d x=0, \quad \forall v(t) \in V$ for a.e. $t \in(0, T)$.

So, we have proved the

Theorem 7. If assumptions of Proposition 5 hold then there exists a unique strong solution $u_{k}$ of $(43)$ such that $u_{k} \in L^{2}(0, T ; V)$, $u_{k t} \in L^{2}\left(0, T ; V^{\prime}\right) \cap L^{2}\left(Q_{\delta}\right) \forall \delta>0, u_{k} \in C\left([0, T] ; L^{2}(-L, 0)\right)$, $u_{k}(x, 0)=u_{0}(x)$, in $[-L, 0], 0 \leq u_{k}(x, t) \leq u_{0}(x)$, in $\bar{Q}_{T}, \phi_{k}\left(u_{k}\right) \in$ $L^{2}\left(\delta, T ; H^{2}(-L, 0)\right)$.

Proof: The uniqueness follows as in Proposition 4.

Moreover,

Theorem 8. If assumptions of Theorem 7 hold, $u_{k}$ is nonincreasing with respect to $t$.

Proof: Let $u_{k}, \hat{u}_{k}$ be the solutions of (43) corresponding to the initial data $u_{0}$, respectively, $\hat{u}_{0}$. Since $u_{k t} \in L^{2}\left(Q_{\delta}\right)$, we have, for $v=s_{\varepsilon}(w)$, $w:=\phi_{k}\left(u_{k}\right)-\phi_{k}\left(\hat{u}_{k}\right)$, going to the limit for $\varepsilon \rightarrow 0$, that

$$
d / d t \int_{-L}^{0}\left(u_{k}-\hat{u}_{k}\right)^{+} d x=\left(u_{k t}-\hat{u}_{k t}, \operatorname{sgn}^{+}\left(\phi_{k}\left(u_{k}\right)-\phi_{k}\left(\hat{u}_{k}\right)\right)\right) \leq 0 .
$$

Integrating (44) from $s$ to $t$, one has, since $u_{k} \in C\left([0, T] ; L^{2}(-L, 0)\right)$,

$$
\begin{aligned}
& \int_{-L}^{0}\left(u_{k}(x, t)-\hat{u}_{k}(x, t)\right)^{+} d x \\
\leq & \int_{-L}^{0}\left(u_{k}(x, s)-\hat{u}_{k}(x, s)\right)^{+} d x \\
\leq & \int_{-L}^{0}\left(u_{0}(x)-\hat{u}_{0}(x)\right)^{+} d x, \quad \forall 0 \leq s \leq t \leq T .
\end{aligned}
$$

Now, if $0 \leq t<t+h \leq T$, (45) gives

$$
\int_{-L}^{0}\left(u_{k}(x, t+h)-u_{k}(x, t)\right)^{+} d x \leq \int_{-L}^{0}\left(u_{k}(x, h)-u_{0}(x)\right)^{+} d x
$$




\section{Estimates on $u_{k}$}

Set $\gamma(\zeta):=\int_{0}^{\zeta} \sqrt{\varphi^{\prime}(\tau)} d \tau$ and $B(\zeta):=\int_{0}^{\zeta} b(\tau) d \tau$, then

$$
-\int_{0}^{t} \int_{-L}^{0} B\left(u_{k}\right)_{x} d x d s \leq(\rho T / 2)\left(u_{0}(-L)^{2}+u_{0}(0)^{2}\right) \leq \rho T .
$$

If in (43) we choose $v=u_{k}$ and integrate from 0 to $t$, we have

$$
\begin{aligned}
(1 / 2) & \int_{-L}^{0}\left|u_{k}(x, t)\right|^{2} d x-(1 / 2) \int_{-L}^{0}\left|u_{k}(x, 0)\right|^{2} d x \\
+ & (1 / k) \int_{0}^{t} \int_{-L}^{0}\left|u_{k x}\right|^{2} d x d s+\int_{0}^{t} \int_{-L}^{0} \varphi\left(u_{k}\right)_{x} u_{k x} d x d s \\
& =-\int_{0}^{t} \nu\left(u_{k}(0, s)\right) q(s) u_{k}(0, s) d s-\int_{0}^{t} \int_{-L}^{0} b\left(u_{k}\right) u_{k x} d x d s
\end{aligned}
$$

because $u_{k} \in C\left([0, T] ; L^{2}(-L, 0)\right)$.

Then by (48) one has

$$
\begin{aligned}
(1 / 2) \int_{0}^{T} \int_{-L}^{0}\left|u_{k}(x, t)\right|^{2} d x d t \leq \int_{0}^{T}\left(\int_{0}^{T} \nu\left(u_{0}(x)\right) q(s) d s\right) d t \\
+\int_{0}^{T} \rho T d t+(1 / 2) \int_{0}^{T} \int_{-L}^{0}\left|u_{k}(x, 0)\right|^{2} d x d t \\
\leq\left(Q T \nu\left(u_{0}(0)\right)+\rho T+(1 / 2)\left\|u_{0}\right\|_{2}^{2}\right) T \\
\leq\left(Q T+\rho T+(1 / 2)\left\|u_{0}\right\|_{2}^{2}\right) T
\end{aligned}
$$

$\left(Q:=\max _{[0, T]} q(t)\right)$, and $(1 / k) \int_{0}^{T} \int_{-L}^{0}\left|u_{k x}\right|^{2} d x d t \leq Q T+\rho T+(1 / 2)\left\|u_{0}\right\|_{2}^{2}$, thus,

$$
\int_{0}^{T} \int_{-L}^{0}\left|u_{k}(x, t)\right|^{2} d x d t+(1 / k) \int_{0}^{T} \int_{-L}^{0}\left|u_{k x}\right|^{2} d x d t \leq C
$$

which implies

$$
\left\|u_{k}\right\|_{L^{2}(0, T ; V)} \leq C \sqrt{k}
$$

(here and through, $C$ denotes various constants independent of $k$ ).

Moreover, by (48) one obtains

$$
\left\|\gamma\left(u_{k}\right)_{x}\right\|_{L^{2}\left(Q_{T}\right)}^{2} \leq T Q+\rho T+(1 / 2)\left\|u_{0}\right\|_{2}^{2},
$$


and

$$
\begin{aligned}
\left\|\gamma\left(u_{k}\right)\right\|_{L^{2}\left(Q_{T}\right)}^{2} & =\int_{0}^{T} \int_{-L}^{0}\left(\int_{0}^{u_{k}} \sqrt{\varphi^{\prime}(\tau)} d \tau\right)^{2} d x d t \\
& \leq \int_{0}^{T} \int_{-L}^{0}\left(\int_{0}^{u_{k}} \varphi^{\prime}(\tau) d \tau\right) u_{k}(x, t) d x d t \\
& \leq \int_{0}^{T} \int_{-L}^{0} \varphi\left(u_{k}\right) u_{k}(x, t) d x d t \\
& \leq \int_{0}^{T} \int_{-L}^{0} \varphi\left(u_{0}\right) u_{0}(x) d x d t \leq C .
\end{aligned}
$$

Therefore,

$$
\left\|\gamma\left(u_{k}\right)\right\|_{L^{2}(0, T ; V)}^{2} \leq C
$$

and by (53) follows that

(56) $\left\|\varphi\left(u_{k}\right)\right\|_{L^{2}(0, T ; V)}^{2}=\int_{0}^{T} \int_{-L}^{0} \varphi\left(u_{k}\right)^{2} d x d t$

$+\int_{0}^{T} \int_{-L}^{0} \varphi^{\prime}\left(u_{k}\right)^{2} u_{k x}^{2} d x d t \leq T \int_{-L}^{0} \varphi\left(u_{0}\right)^{2} d x+Q^{\prime}\left\|\gamma\left(u_{k}\right)_{x}\right\|_{L^{2}\left(Q_{T}\right)}^{2} \leq C$

$\left(Q^{\prime}:=\left\|\varphi^{\prime}\left(u_{k}\right)\right\|_{L^{\infty}\left(Q_{T}\right)}\right.$, independent of $\left.k\right)$.

Now, (52) and (56) give

(57) $\left\|\phi_{k}\left(u_{k}\right)\right\|_{L^{2}(0, T ; V)}^{2} \leq 2\left\|\varphi\left(u_{k}\right)\right\|_{L^{2}(0, T ; V)}^{2}+(2 / k)\left\|u_{k}\right\|_{L^{2}(0, T ; V)}^{2} \leq C$.

From (43) and (57) we have that

$$
\left\|u_{k t}\right\|_{L^{2}\left(0, T ; V^{\prime}\right)} \leq C
$$

Set $\xi_{k}:=\gamma\left(u_{k}\right)$, by $(55) \xi_{k}$ is bounded in $L^{2}(0, T ; V) \subset L^{2}(0, T$; $\left.W^{s, 2}(-L, 0)\right), 0<s<1$.

Now, $u_{k}=\gamma^{-1}\left(\xi_{k}\right)$ and if we suppose that

$$
\gamma^{-1} \text { is Hölder continuous of order } \theta \in(0,1),
$$

for a classical result due to $[\mathbf{3}]$, one has

$$
\left\|u_{k}(t)\right\|_{W^{\theta s, 2 / \theta}(-L, 0)}^{1 / \theta} \leq\left\|\xi_{k}(t)\right\|_{W^{s, 2}(-L, 0)}\left\|\gamma^{-1}\right\|_{\text {Hölder }}^{1 / \theta}
$$


that integrate with respect to $t$, gives

(61) $\left\|u_{k}\right\|_{L^{2 / \theta}\left(0, T ; W^{\theta s, 2 / \theta}(-L, 0)\right)}^{2 / \theta} \leq\left\|\xi_{k}\right\|_{L^{2}\left(0, T ; W^{s, 2}(-L, 0)\right)}^{2}\left\|\gamma^{-1}\right\|_{\text {Hölder }}^{2 / \theta}$ $\leq C$, because of (55).

Again by [3],

$$
W^{\theta s, 2 / \theta}(-L, 0) \subset L^{2 / \theta}(-L, 0)
$$

with compact injection, as

$$
W^{\theta s, 2 / \theta}(-L, 0) \subset L^{2 / \theta}(-L, 0) \subset L^{2}(-L, 0) \subset V^{\prime},
$$

the set

$$
\tilde{W}(0, T):=\left\{v \in L^{2 / \theta}\left(0, T ; W^{\theta s, 2 / \theta}(-L, 0)\right): v_{t} \in L^{2}\left(0, T ; V^{\prime}\right)\right\}
$$

is compactly embedded in $L^{2 / \theta}\left(0, T ; L^{2 / \theta}(-L, 0)\right)$ (see [8]).

By (Thm 7), (58) and (61), there exists a subsequence still denoted by $u_{k}$, such that when $k \rightarrow \infty$

(65) $u_{k} \rightarrow u$ in $L^{\infty}\left(0, T ; L^{2}(-L, 0)\right)-{ }^{*}$ weak as consequence of (Thm 7$)$;

(66) $u_{k} \rightarrow u$ in $L^{2}\left(Q_{T}\right)$ and a.a. because of (58) and (61);

(67) $u_{k t} \rightarrow u_{t}$ in $L^{2}\left(0, T ; V^{\prime}\right)$ by $(58)$

and

$$
\left\|u_{t}\right\|_{L^{2}\left(0, T ; V^{\prime}\right)} \leq C
$$

$u_{k}$ verifies the condition $0 \leq u_{k}(x, t) \leq u_{0}(x)$ in $\bar{Q}_{T}$, hence it follows that

$$
\left\|u_{k}\right\|_{L^{\infty}\left(Q_{T}\right)} \leq C
$$

$$
\varphi\left(u_{k}\right) \rightarrow \varphi(u) \text { in } L^{2}(0, T ; V)
$$

because of (56); one verifies that the limit is $\varphi(u)$ for $(66)$ and the Lebesgue's Theorem.

By (57) and (52) it follows that

$$
\phi_{k}\left(u_{k}\right)-\varphi(u) \text { in } L^{2}(0, T ; V),
$$


since $\phi_{k}\left(u_{k}\right)-\varphi\left(u_{k}\right)=(1 / k) u_{k} \rightarrow 0$ in $L^{2}(0, T ; V)$.

A classic result, implies that for subsequence,

$$
u_{k} \rightarrow u \text { in } C\left([0, T] ; V^{\prime}\right)
$$

because of (61) and (67).

By (65) and (72) it follows that $u \in C_{s}\left([0, T] ; L^{2}(-L, 0)\right)$ where $C_{s}\left([0, T] ; L^{2}(-L, 0)\right)$ is the space of functions $u \in L^{\infty}\left(0, T ; L^{2}(-L, 0)\right)$ such that $t \rightarrow(u(t), v)$ is continuous on $[0, T], \forall v \in L^{2}(-L, 0)$. Finally, since $u_{k}(0) \rightarrow u(0)$ in $V^{\prime}$ as $k \rightarrow \infty$ for (72), we have that $u(0)=u_{0}$.

By the Lebesgue's Theorem and (66) it follows that

$$
b\left(u_{k}\right) \rightarrow b(u) \text { in } L^{2}\left(Q_{T}\right) \text { for } k \rightarrow \infty,
$$

because $b\left(u_{k}\right) \rightarrow b(u)$ a.a. when $k \rightarrow \infty$.

\section{4. $L^{1}$ estimates on $u_{k}$}

We are interested to obtain a better estimate on the time derivative for $u_{k}$ and on $\phi_{k}\left(u_{k}\right)$. Now, if we consider assumption (18) which assure the monotonicity with respect to $t$ of $u_{k}$, we are able to show that there exists a constant $C>0$ such that $u_{k}$ verifies

$$
\left\|u_{k}(t+\tau)-u_{k}(t)\right\|_{L^{1}(-L, 0)} \leq C \tau, \forall \tau \in(0, T), \forall t \in[0, T-\tau]
$$

and

$$
\left\|u_{k t}\right\|_{L^{\infty}\left(0, T ; L^{1}(-L, 0)\right)} \leq C .
$$

In fact, choosing $v=1, v \in V$, in (43) we have

$$
\int_{t}^{t+\tau}\left(u_{k s}, 1\right)_{V^{\prime}, V} d s+\int_{t}^{t+\tau} \nu\left(u_{k}(0, s)\right) q(s) d s=0
$$

which implies that

$$
\left\|u_{k}(t+\tau)-u_{k}(t)\right\|_{L^{1}(-L, 0)}=-\int_{-L}^{0}\left(u_{k}(x, t+\tau)-u_{k}(t)\right) d x \leq C \tau,
$$

since $\left|\nu\left(u_{k}(0, s)\right) q(s)\right| \leq C$ with $C$ independent of $s$. For (75) see the proof of the Proposition 11.

Properties (74) and (75) hold also without reference to a class of monotonic functions as we are going to show.

Let us recall some results that will be used in the following. 
Lemma 9. For any $v \in V, \lim _{\eta \rightarrow 0^{+}} \int_{[x \in[-L, 0]:|v(x)|<\eta]}\left|v_{x}\right| d x=0$ (see [9]).

$$
\operatorname{sgn}(x)\left\{\begin{array} { l l } 
{ = 1 , } & { x > 0 } \\
{ = 0 , } & { x = 0 } \\
{ = - 1 , } & { x < 0 }
\end{array} \quad \operatorname { s g n } _ { \eta } ( x ) \left\{\begin{array}{ll}
=1, & x>\eta \\
=x / \eta, & |x| \leq \eta, \eta>0 \\
=-1, & x<-\eta .
\end{array}\right.\right.
$$

The function $\operatorname{sgn}_{\eta}$ is a Lipschitz function on $\mathbb{R}$.

Lemma 10. For any $p, 1 \leq p \leq \infty$, if $v \in L^{p}(-L, 0)$, then $\operatorname{sgn}_{\eta}(v) \rightarrow$ $\operatorname{sgn}(v)$ in $L^{p}(-L, 0)$, when $\eta \rightarrow 0$ (see [9]).

To obtain an estimate on $u_{k t}$ uniformly with respect to $k$, we assume the following condition

$$
\begin{aligned}
0 \leq u_{0} \leq 1, \text { a.a. in }(-L, 0), & \varphi\left(u_{0}\right) \in V \\
& \text { and } \varphi\left(u_{0}\right)_{x}+b\left(u_{0}\right) \in B V(-L, 0) .
\end{aligned}
$$

We can prove

Proposition 11. If assumptions $\left(H_{\varphi}\right),\left(H_{b}\right),\left(H_{\nu}\right),\left(H_{q}\right)$ are satisfied and (76) holds, there exists a constant $C>0$ such that $u_{k}$ verifies (74) and (75).

Proof: For $0<s<s+\tau<T, \tau \in(0, T), \forall v(t) \in V$, for a.a. $t \in(0, T)$ we consider

$$
\begin{aligned}
& \left(u_{k s}(s+\tau), v\right)+\nu\left(u_{k}(0, s+\tau)\right) q(s+\tau) v(0, s) \\
& \quad+\int_{-L}^{0} \phi_{k}\left(u_{k}(s+\tau)\right)_{x} v_{x} d x+\int_{-L}^{0} b\left(u_{k}(s+\tau)\right) v_{x} d x=0
\end{aligned}
$$

$$
\begin{aligned}
\left(u_{k s}(s), v\right)+\nu( & \left.u_{k}(0, s)\right) q(s) v(0, s) \\
& +\int_{-L}^{0} \phi_{k}\left(u_{k}(s)\right)_{x} v_{x} d x+\int_{-L}^{0} b\left(u_{k}(s)\right) v_{x} d x=0 .
\end{aligned}
$$

Subtracting (78) to (77), we obtain

$$
\begin{aligned}
& \left(u_{k s}(s+\tau)-u_{k s}(s), v\right) \\
& \left.+\left(\nu\left(u_{k}(0, s+\tau)\right) q(s+\tau)\right) q(s+\tau)-\nu\left(u_{k}(0, s)\right) q(s)\right) v(0, s) \\
& \quad+\int_{-L}^{0}\left(\phi_{k}\left(u_{k}(s+\tau)\right)-\phi_{k}\left(u_{k}(s)\right)\right)_{x} v_{x} d x \\
& \quad+\int_{-L}^{0}\left(b\left(u_{k}(s+\tau)\right)-b\left(u_{k}(s)\right)\right) v_{x} d x=0
\end{aligned}
$$


choosing $v(s):=\operatorname{sgn}_{\eta}\left(\phi_{k}\left(u_{k}(s+\tau)\right)-\phi_{k}\left(u_{k}(s)\right)\right) \in V$ in (79), one has

$$
\begin{array}{r}
\left(u_{k s}(s+\tau)-u_{k s}(s), \operatorname{sgn}_{\eta}\left(\phi_{k}\left(u_{k}(s+\tau)\right)-\phi_{k}\left(u_{k}(s)\right)\right)\right) \\
+\left(\nu\left(u_{k}(0, s+\tau)\right) q(s+\tau)-\nu\left(u_{k}(0, s)\right) q(s)\right) \operatorname{sgn}_{\eta}\left(\phi_{k}\left(u_{k}(0, s+\tau)\right)\right. \\
\left.-\phi_{k}\left(u_{k}(0, s)\right)\right)+\int_{-L}^{0}\left(\phi_{k}\left(u_{k}(s+\tau)\right)-\phi_{k}\left(u_{k}(s)\right)\right)_{x}\left(\operatorname { s g n } _ { \eta } \left(\phi_{k}\left(u_{k}(s+\tau)\right)\right.\right. \\
\left.\left.-\phi_{k}\left(u_{k}(s)\right)\right)\right)_{x} d x+\int_{-L}^{0}\left(b\left(u_{k}(s+\tau)\right)-b\left(u_{k}(s)\right)\right)\left(\operatorname { s g n } _ { \eta } \left(\phi_{k}\left(u_{k}(s+\tau)\right)\right.\right. \\
\left.\left.-\phi_{k}\left(u_{k}(s)\right)\right)\right)_{x} d x=0 .
\end{array}
$$

Now,

$$
\begin{aligned}
& \mid \int_{-L}^{0}\left(b\left(u_{k}(s+\tau)\right)-b\left(u_{k}(s)\right)\right)\left(\operatorname { s g n } _ { \eta } \left(\phi_{k}\left(u_{k}(s+\tau)\right)\right.\right. \\
& \left.\left.-\phi_{k}\left(u_{k}(s)\right)\right)\right)_{x} d x \mid \\
& =\mid \int_{\left[\left|z_{k}(s+\tau)-z_{k}(s)\right|<\eta\right]}\left(b\left(\phi_{k}^{-1}\left(z_{k}(s+\tau)\right)\right)\right. \\
& \left.-b\left(\phi_{k}^{-1}\left(z_{k}(s)\right)\right)\right)(1 / \eta)\left(z_{k}(s+\tau)-z_{k}(s)\right)_{x} d x \mid
\end{aligned}
$$

(where $z_{k}(\sigma):=\phi_{k}\left(u_{k}(\sigma)\right)$ )

$$
\leq \hat{c} \int_{\left[\left|z_{k}(s+\tau)-z_{k}(s)\right|<\eta\right]}\left|\left(z_{k}(s+\tau)-z_{k}(s)\right)_{x}\right| d x
$$

(since $b \circ \phi_{k}^{-1}$ is Lipschitz continuous with constant $\hat{c}$ ).

Since $z_{k}(s+\tau)-z_{k}(s) \in V$, Lemma 9 implies that

$$
\lim _{\eta \rightarrow 0^{+}} \int_{\left[\left|z_{k}(s+\tau)-z_{k}(s)\right|<\eta\right]}\left|\left(z_{k}(s+\tau)-z_{k}(s)\right)_{x}\right| d x=0
$$

hence, by the Lebesgue's Theorem we obtain

(83) $\lim _{\eta \rightarrow 0^{+}} \int_{\delta}^{t} \int_{-L}^{0}\left(b\left(u_{k}(s+\tau)\right)\right.$

$$
\left.-b\left(u_{k}(s)\right)\right)\left(\operatorname{sgn}_{\eta}\left(\phi_{k}\left(u_{k}(s+\tau)\right)-\phi_{k}\left(u_{k}(s)\right)\right)\right)_{x} d x=0 .
$$


Moreover,

$$
\begin{aligned}
& \int_{-L}^{0}\left(\phi_{k}\left(u_{k}(s+\tau)\right)-\phi_{k}\left(u_{k}(s)\right)\right)_{x}\left(\operatorname { s g n } _ { \eta } \left(\phi_{k}\left(u_{k}(s+\tau)\right)\right.\right. \\
& \left.\left.-\phi_{k}\left(u_{k}(s)\right)\right)\right)_{x} d x=\frac{1}{\eta} \int_{-L}^{0}\left|\left(\phi_{k}\left(u_{k}(s+\tau)\right)-\phi_{k}\left(u_{k}(s)\right)\right)_{x}\right|^{2} d x \geq 0
\end{aligned}
$$

by $\left(H_{\nu}\right)$ and $\left(H_{q}\right)$

$$
\begin{aligned}
& \mid\left(\nu\left(u_{k}(0, s+\tau)\right) q(s+\tau)\right. \\
& \left.\quad-\nu\left(u_{k}(0, s)\right) q(s)\right) \operatorname{sgn}_{\eta}\left(\phi_{k}\left(u_{k}(0, s+\tau)\right)-\phi_{k}\left(u_{k}(0, s)\right)\right) \mid \leq C
\end{aligned}
$$

with $C$ a constant independent of $s$.

Thus because of (84) and (85), equality (80) gives us

$$
\begin{aligned}
& \text { (86) }\left(u_{k s}(s+\tau)-u_{k s}(s), \operatorname{sgn}_{\eta}\left(\phi_{k}\left(u_{k}(s+\tau)\right)-\phi_{k}\left(u_{k}(s)\right)\right)\right) \leq C \\
& +\mid \int_{-L}^{0}\left(b\left(u_{k}(s+\tau)-b\left(u_{k}(s)\right)\right)\left(\operatorname{sgn}_{\eta}\left(\phi_{k}\left(u_{k}(s+\tau)\right)-\phi_{k}\left(u_{k}(s)\right)\right)\right)_{x} d x \mid .\right.
\end{aligned}
$$

Integrating (86) on $[\delta, t], t \in(\delta, T-\tau]$ and going to the limit as $\eta \rightarrow 0^{+}$, because of $(83)$, one has

$$
\begin{aligned}
& \text { (87) } \left.\int_{-L}^{0}\left(u_{k}(t+\tau)-u_{k}(t)\right) \operatorname{sgn}\left(\phi_{k}\left(u_{k}(t+\tau)\right)-\phi_{k}\left(u_{k}(t)\right)\right)\right) d x \\
& \left.\leq \int_{-L}^{0}\left(u_{k}(\delta+\tau)-u_{k}(\delta)\right) \operatorname{sgn}\left(\phi_{k}\left(u_{k}(\delta+\tau)\right)-\phi_{k}\left(u_{k}(\delta)\right)\right)\right) d x+C(\tau-\delta)
\end{aligned}
$$

$\forall \delta>0, \forall t \in(\delta, T-\tau]$.

Since $\phi_{k}(\cdot)$ is increasing, then $\operatorname{sgn}\left(\phi_{k}\left(u_{k}(s+\tau)\right)-\phi_{k}\left(u_{k}(s)\right)\right)=$ $\operatorname{sgn}\left(u_{k}(s+\tau)-u_{k}(s)\right)$, thus (87) gives us

$$
\int_{-L}^{0}\left|u_{k}(t+\tau)-u_{k}(t)\right| d x \leq \int_{-L}^{0}\left|u_{k}(\delta+\tau)-u_{k}(\delta)\right| d x+C(\tau-\delta)
$$

$\forall \delta>0, \forall t \in(\delta, T-\tau]$. But $u_{k} \in C\left([0, T] ; L^{2}(-L, 0)\right)$, hence when $\delta \rightarrow 0^{+}$we have

$$
\int_{-L}^{0}\left|u_{k}(t+\tau)-u_{k}(t)\right| d x \leq \int_{-L}^{0}\left|u_{k}(\tau)-u_{0}\right| d x+C \tau
$$

$$
\forall t \in[0, T-\tau]
$$


We look for an uniform estimate with respect to $k$ for $\int_{-L}^{0} \mid u_{k}(\tau)-$ $u_{0} \mid d x$.

For this, we take $v:=\operatorname{sgn}_{\eta}\left(\phi_{k}\left(u_{k}\right)-\phi_{k}\left(u_{0}\right)\right) \in V$ in $(78)$ and $s \in(\delta, \tau)$. Then,

$$
\begin{array}{r}
\left(u_{k s}, \operatorname{sgn}_{\eta}\left(\phi_{k}\left(u_{k}\right)-\phi_{k}\left(u_{0}\right)\right)\right)+\nu\left(u_{k}(0, s)\right) q(s) \operatorname{sgn}_{\eta}\left(\phi_{k}\left(u_{k}(0, s)\right)\right. \\
\left.-\phi_{k}\left(u_{0}(0)\right)\right)+\int_{-L}^{0}\left(\phi_{k}\left(u_{k}\right)\right)_{x}\left(\operatorname{sgn}_{\eta}\left(\phi_{k}\left(u_{k}\right)-\phi_{k}\left(u_{0}\right)\right)\right)_{x} d x \\
+\int_{-L}^{0} b\left(u_{k}\right)\left(\operatorname{sgn}_{\eta}\left(\phi_{k}\left(u_{k}\right)-\phi_{k}\left(u_{0}\right)\right)\right)_{x} d x=0
\end{array}
$$

hence

(91) $\left(u_{k s}, \operatorname{sgn}_{\eta}\left(\phi_{k}\left(u_{k}\right)-\phi_{k}\left(u_{0}\right)\right)\right)+\nu\left(u_{k}(0, s)\right) q(s) \operatorname{sgn}_{\eta}\left(\phi_{k}\left(u_{k}(0, s)\right)\right.$

$$
\left.-\phi_{k}\left(u_{0}(0)\right)\right)+\int_{-L}^{0}\left(\left(\phi_{k}\left(u_{k}\right)-\phi_{k}\left(u_{0}\right)\right)_{x}+b\left(u_{k}\right)-b\left(u_{0}\right)\right)\left(\operatorname { s g n } _ { \eta } \left(\phi_{k}\left(u_{k}\right)\right.\right.
$$

$\left.\left.-\phi_{k}\left(u_{0}\right)\right)\right)_{x} d x=-\int_{-L}^{0}\left(\left(\phi_{k}\left(u_{0}\right)\right)_{x}+b\left(u_{0}\right)\right)\left(\operatorname{sgn}_{\eta}\left(\phi_{k}\left(u_{k}\right)-\phi_{k}\left(u_{0}\right)\right)\right)_{x} d x$.

Proceeding as above, one proves that

$$
\begin{aligned}
& \int_{-L}^{0}\left(\phi_{k}\left(u_{k}\right)-\phi_{k}\left(u_{0}\right)\right)_{x}\left(\operatorname{sgn}_{\eta}\left(\phi_{k}\left(u_{k}\right)-\phi_{k}\left(u_{0}\right)\right)\right)_{x} d x \geq 0 ; \\
& \left|\nu\left(u_{k}(0, s)\right) q(s) \operatorname{sgn}_{\eta}\left(\phi_{k}\left(u_{k}(0, s)\right)-\phi_{k}\left(u_{0}(0)\right)\right)\right| \leq C
\end{aligned}
$$

with $C$ independent of $s$;

$$
\lim _{\eta \rightarrow 0^{+}} \int_{\delta}^{\tau} \int_{-L}^{0}\left(b\left(u_{k}\right)-b\left(u_{0}\right)\right)\left(\operatorname{sgn}_{\eta}\left(\phi_{k}\left(u_{k}\right)-\phi_{k}\left(u_{0}\right)\right)\right)_{x} d x=0 .
$$

Therefore

$$
\begin{aligned}
& \left(u_{k s}, \operatorname{sgn}_{\eta}\left(\phi_{k}\left(u_{k}\right)-\phi_{k}\left(u_{0}\right)\right)\right) \\
& \quad \leq C+\left|\int_{-L}^{0}\left(b\left(u_{k}\right)-b\left(u_{0}\right)\right) \operatorname{sgn}_{\eta}\left(\phi_{k}\left(u_{k}\right)-\phi_{k}\left(u_{0}\right)\right)_{x} d x\right| .
\end{aligned}
$$

Integrating (95) from $\delta$ to $\tau$ and going to the limit when $\eta \rightarrow 0^{+}$we have because of (76), (92), (93) and (94) that

$$
\int_{-L}^{0}\left|u_{k}(\tau)-u_{0}\right| d x \leq C \tau
$$


for $\delta \rightarrow 0^{+}$, because $u_{k} \in C\left([0, T] ; L^{2}(-L, 0)\right)$.

Thus, (89) and (96) gives us

$$
\left\|u_{k}(t+\tau)-u_{k}(t)\right\|_{L^{1}(-L, 0)} \leq C \tau .
$$

Now, $u_{k t} \in L^{2}\left(Q_{\delta}\right), \forall \delta>0$ hence $(1 / \tau)\left|u_{k}(t+\tau)-u_{k}(t)\right| \rightarrow u_{k t}(t)$ in $L^{2}\left(Q_{\delta}\right)$, and in $L^{2}(-L, 0)$ for a.a. $t \in(\delta, T)$. Thus (97) gives us (75), because $C$ is independent of $\delta$.

This ends the proof.

\section{Existence of solutions for degenerate problem}

By definition, $\phi_{k}(\cdot) \in C^{1}([0,1])$ and as for as above, one has

$$
\left\|\phi_{k}\left(u_{k}\right)_{t}\right\|_{L^{\infty}\left(0, T ; L^{1}(-L, 0)\right)} \leq C .
$$

By (57) and (98) it follows that

$$
\left\|\phi_{k}\left(u_{k}\right)\right\|_{H^{1,1}\left(0, T ; L^{1}(-L, 0)\right)} \leq C .
$$

Hence,

$$
\phi_{k}\left(u_{k}\right) \text { is bounded in } L^{\infty}\left(Q_{T}\right) \cap H^{1,1}\left(0, T ; L^{1}(-L, 0)\right) .
$$

The (57) and (98) say that $\phi_{k}\left(u_{k}\right) \in W(0, T)$, therefore

$$
\phi_{k}\left(u_{k}\right) \rightarrow \varphi(u) \quad \text { in } L^{1}\left(Q_{T}\right) \text { as } k \rightarrow \infty .
$$

Hence, $\varphi(u) \in B V\left(0, T ; L^{1}(-L, 0)\right)$, because it is the limit of a sequence in $L^{\infty}\left(Q_{T}\right) \cap H^{1,1}\left(0, T ; L^{1}(-L, 0)\right)$.

By (66), $u_{k} \rightarrow u$ in $L^{1}\left(Q_{T}\right)$, moreover, (69) and (75) imply that $u_{k}$ is bounded in $L^{\infty}\left(Q_{T}\right) \cap H^{1,1}\left(0, T ; L^{1}(-L, 0)\right)$, hence $u \in B V(0, T$; $\left.L^{1}(-L, 0)\right)$; a such $u$ has a trace for $t=0$.

Since $\phi_{k}\left(u_{k}\right)_{t}$ weakly converges to $\varphi(u)_{t}$ in $L^{2}\left(Q_{\delta}\right), \forall \delta>0$ as $k \rightarrow$ $\infty$, we obtain the estimate: $\left\|\varphi(u)_{t}\right\|_{L^{2}\left(\delta, T ; L^{1}(-L, 0)\right)} \leq C$, where $C$ is a constant independent of $\delta$. Thus, $\left\|\varphi(u)_{t}\right\|_{L^{2}\left(0, T ; L^{1}(-L, 0)\right)} \leq C$ and consequently, since $V \subset L^{\infty}(-L, 0)$ with continuous injection, $\left\|\varphi(u)_{t}\right\|_{L^{2}\left(0, T ; V^{\prime}\right)} \leq C$.

Then, $\varphi(u) \in C\left([0, T] ; L^{2}(-L, 0)\right)$ and the Hölder continuity of $\varphi^{-1}$ implies that $u \in C\left([0, T] ; L^{2}(-L, 0)\right)$. Moreover, $u \in L^{\infty}\left(Q_{T}\right)$ and $\varphi(u) \in L^{\infty}\left(Q_{T}\right) \cap H^{1}\left(Q_{T}\right)$. Finally, the trace in $t=0$ for $u$ in $L^{1}(-L, 0)$ coincides with $u_{0}$.

Thus, we have proved the following existence result

Theorem 12. If $\left(H_{\varphi}\right),\left(H_{b}\right),\left(H_{\nu}\right),\left(H_{q}\right)$ and (76) hold, then there exists a strong solution for problem (1)-(4). 


\section{Uniqueness of solution for degenerate problem}

To study this problem, we introduce in $\mathbb{R}^{2}$ the one dimensional Hausdorff's measure $\mathcal{H}_{1}$ (for a definition, see [4]). Since $\varphi$ is an homeomorphism and $\varphi(u) \in L^{\infty}\left(Q_{T}\right) \cap H^{1}\left(Q_{T}\right)$, in [6, Lemmas 1 and 2], is proved that $\varphi(u)$ and any solution $u$ of (1)-(4) are $\mathcal{H}_{1}$-a.a. $\mathcal{L}^{2}$-approximately continuous on $Q_{T}$ (see [4, pg. 158]).

Now $u \in B V\left(0, T ; L^{1}(-L, 0)\right)$ hence its distributional time derivative $u_{t}$ is an integrable Radon's measure on $Q_{T}, \mathcal{H}_{1}$ absolutely continuous (see [6]). This means that $u_{t}$ do not charge the complementary set of $\mathcal{L}^{2}$ approximate continuity points of $u$, thus we can utilize the integration by parts formula.

Let $u, \hat{u}$ be solutions for (1)-(4) with initial data $u_{0}$, respectively, $\hat{u}_{0}$. Then

$$
\begin{aligned}
& \int_{0}^{t}\left(u_{t}-\hat{u}_{t}, v\right)_{V^{\prime}, V} \rho(\tau) d \tau \\
+ & \int_{0}^{t}(\nu(u(0, \tau))-\nu(\hat{u}(0, \tau)) q(\tau) v(0, \tau) \rho(\tau) d \tau \\
+ & \int_{0}^{t} \int_{-L}^{0}(\varphi(u)-\varphi(\hat{u}))_{x} v_{x} \rho(\tau) d x d \tau \\
+ & \int_{0}^{t} \int_{-L}^{0}(b(u)-b(\hat{u})) v_{x} \rho(\tau) d x d \tau=0
\end{aligned}
$$

$\forall v \in L^{2}(0, T ; V), \forall t>0$ and $\rho \in \mathcal{D}(0, t), \rho(t) \geq 0$.

Set $w:=\varphi(u)-\varphi(\hat{u})$ and $H_{\eta}(w):=w^{+2} /\left(w^{2}+\eta\right), \eta>0$ and suppose that

$$
\left|b\left(\varphi^{-1}(t)\right)-b\left(\varphi^{-1}(s)\right)\right| \leq c^{\prime}|t-s|^{1 / 2} .
$$

It is easy to prove that, $\forall r \in \mathbb{R}$,

$$
\lim _{\eta \rightarrow 0^{+}} r H_{\eta}^{\prime}(r)=0,0 \leq H_{\eta}(r) \leq 1 \text { and } 0 \leq r H_{\eta}^{\prime}(r) \leq 1 / 2 .
$$

Choosing $v=H_{\eta}(w) \in H^{1}\left(Q_{T}\right)$ in (102) one has,

$$
\int_{0}^{t}(\nu(u(0, \tau))-\nu(\hat{u}(0, \tau))) q(\tau) H_{\eta}(w(0, \tau)) \rho(\tau) d \tau \geq 0
$$


because $\varphi$ is increasing, then

$$
\begin{aligned}
& \int_{0}^{t}\left(u_{t}-\hat{u}_{t}, H_{\eta}(w)\right)_{V^{\prime} V} \rho(\tau) d \tau \\
+ & \int_{0}^{t} \int_{-L}^{0}\left|(\varphi(u)-\varphi(\hat{u}))_{x}\right|^{2} H_{\eta}^{\prime}(w) \rho(\tau) d x d \tau \\
+ & \int_{0}^{t} \int_{-L}^{0}(b(u)-b(\hat{u})) H_{\eta}(w)_{x} \rho(\tau) d x d \tau \leq 0 .
\end{aligned}
$$

Now,

(106)

$$
\begin{aligned}
& -\int_{0}^{t} \int_{-L}^{0}(b(u)-b(\hat{u})) H_{\eta}(w)_{x} \rho(\tau) d x d \tau \\
& -\int_{0}^{t} \int_{-L}^{0}(b(u)-b(\hat{u}))(\varphi(u)-\varphi(\hat{u}))_{x} H_{\eta}^{\prime}(w) \rho(\tau) d x d \tau \\
& \leq \int_{0}^{t} \int_{-L}^{0}|b(u)-b(\hat{u})|\left|(\varphi(u)-\varphi(\hat{u}))_{x}\right| H_{\eta}^{\prime}(w) \rho(\tau) d x d \tau \\
& \leq c^{\prime} \int_{0}^{t} \int_{-L}^{0}|s-\hat{s}|^{1 / 2}\left|(s-\hat{s})_{x}\right| H_{\eta}^{\prime}(s-\hat{s}) \rho(\tau) d x d \tau \\
& \leq(1 / 2) \int_{0}^{t} \int_{-L}^{0}\left|(s-\hat{s})_{x}\right|^{2} H_{\eta}^{\prime}(s-\hat{s}) \rho(\tau) d x d \tau \\
& +c_{1} \int_{0}^{t} \int_{-L}^{0}|s-\hat{s}| H_{\eta}^{\prime}(s-\hat{s}) \rho(\tau) d x d \tau
\end{aligned}
$$

by (103) with $s:=\varphi(u), \hat{s}:=\varphi(\hat{u})$ and the inequality of Young.

Therefore, (105) gives us

$$
\begin{gathered}
\int_{0}^{t}\left(u_{t}-\hat{u}_{t}, H_{\eta}(w)\right)_{V^{\prime} V} \rho(\tau) d \tau \\
+(1 / 2) \int_{0}^{t} \int_{-L}^{0}\left|(s-\hat{s})_{x}\right|^{2} H_{\eta}^{\prime}(s-\hat{s}) \rho(\tau) d x d \tau \\
\leq c_{1} \int_{0}^{t} \int_{-L}^{0}|s-\hat{s}| H_{\eta}^{\prime}(s-\hat{s}) \rho(\tau) d x d \tau
\end{gathered}
$$

which implies

$$
\begin{aligned}
& \int_{0}^{t}\left(u_{t}-\hat{u}_{t}, H_{\eta}(w)\right)_{V^{\prime} V} \rho(\tau) d \tau \\
& \leq c_{1} \int_{0}^{t} \int_{-L}^{0}|s-\hat{s}| H_{\eta}^{\prime}(s-\hat{s}) \rho(\tau) d x d \tau .
\end{aligned}
$$


$H_{\eta}(\cdot)$ is an $C^{1}$ approximation of the Heaviside's function and as far as above claimed in (104) and by the Lebesgue's Theorem, we have

$$
\lim _{\eta \rightarrow 0^{+}} \int_{0}^{t} \int_{-L}^{0}|s-\hat{s}| H_{\eta}^{\prime}(s-\hat{s}) \rho(\tau) d x d \tau=0
$$

Now, we treat the term $\int_{0}^{t}\left(u_{t}-\hat{u}_{t}, H_{\eta}(w)\right)_{V^{\prime} V} \rho(\tau) d \tau$.

We known that $u-\hat{u} \in L^{2}\left(Q_{T}\right)$ and $(u-\hat{u})_{t} \in L^{2}\left(0, T ; V^{\prime}\right), \rho H_{\eta}(w) \in$ $L^{2}(0, T ; V)\left(H_{\eta}(w) \in H^{1}\left(Q_{T}\right) \cap L^{\infty}\left(Q_{T}\right)\right)$ and $\left(\rho H_{\eta}(w)\right)_{t} \in L^{2}\left(Q_{T}\right)$.

Since $V$ is embedded in $L^{2}(-L, 0)$ with dense and continuous injection, then defined the intermediate spaces $Y:=\left[V, L^{2}\right]_{1 / 2}$ and $Y^{\prime}:=$ $\left[L^{2}, V^{\prime}\right]_{1 / 2}$ (see $\left[\mathbf{8}\right.$, pg. 11]) one has that $u-\hat{u} \in C\left([0, T] ; Y^{\prime}\right), \rho H_{\eta} \in$ $C([0, T] ; Y)$ and the following formula holds

$$
\begin{aligned}
& \text { (109) } \int_{0}^{t}\left(u_{t}-\hat{u}_{t}, H_{\eta}(w)\right)_{V^{\prime} V} \rho(\tau) d \tau=\left\langle u(t)-\hat{u}(t), H_{\eta}(w(t)) \rho(t)\right\rangle_{Y^{\prime} Y} \\
& -\left\langle u(0)-\hat{u}(0), H_{\eta}(w(0)) \rho(0)\right\rangle_{Y^{\prime} Y}-\int_{0}^{t} \int_{-L}^{0}(u-\hat{u})\left(\rho H_{\eta}(w)\right)_{t} d x d \tau .
\end{aligned}
$$

But $u \in C_{s}\left([0, T] ; L^{2}(-L, 0)\right)$, so the pairing of duality $Y^{\prime}, Y$ is an integral in $L^{2}(-L, 0)$ (see [11, Chapter III]) and for $\rho \in \mathcal{D}(0, t)(109)$ becomes

$$
\begin{aligned}
& \int_{0}^{t}\left(u_{t}-\hat{u}_{t}, H_{\eta}(w)\right)_{V^{\prime} V} \rho(\tau) d \tau \\
&=-\int_{0}^{t} \int_{-L}^{0}(u-\hat{u})\left(\rho H_{\eta}(w)\right)_{t} d x d \tau
\end{aligned}
$$

To the purpose of apply the results of [11, Chapter II], see also [2], we work with the Borelian representative $\bar{u}$ of $u$ in the $\mathcal{L}^{2}$-a.a. class (that is $u=\bar{u} \mathcal{L}^{2}$-a.a.), this allow to use the Borel measure. We agree to write

$$
-\int_{0}^{t} \int_{-L}^{0}(u-\hat{u})\left(\rho H_{\eta}(w)\right)_{t} d x d \tau=-\int_{Q_{t}}(u-\hat{u})\left(\rho H_{\eta}(w)\right)_{t}
$$

because $\rho H_{\eta}(w) \in H^{1}\left(Q_{T}\right)$, belongs to $B V\left(0, T ; L^{1}(-L, 0)\right)$ and the Borel measure $\left(\rho H_{\eta}(w)\right)_{t}$ is $\mathcal{L}^{2}$-Lebesgue absolutely continuous, with density $\left(\rho H_{\eta}(w)\right)_{t}$. 
Moreover, $u-\hat{u} \in B V\left(0, T ; L^{1}(-L, 0)\right) \cap L^{\infty}\left(Q_{T}\right), \rho H_{\eta}(w) \in$ $L^{\infty}\left(Q_{T}\right) \cap H^{1}\left(Q_{T}\right)$ ad $(u-\hat{u})_{t}$ is a Radon's measure $\mathcal{H}_{1}$-absolutely continuous, by a result of [12, sections 13.2 and 14.4], $(u-\hat{u}) \rho H_{\eta}(w) \in$ $B V\left(0, T ; L^{1}(-L, 0)\right)$ and we can use in (110) the formula of integration by parts (see [2] and [11]) to obtain

$$
\int_{0}^{t}\left(u_{t}-\hat{u}_{t}, H_{\eta}(w)\right)_{V^{\prime} V} \rho(\tau) d \tau=\int_{Q_{t}} \rho(t) H_{\eta}(w)(u-\hat{u})_{t} .
$$

Taking in consideration that $H_{\eta}$ converges pointwise to $\operatorname{sgn}^{+}$as $\eta \rightarrow 0^{+}$ and $\varphi(u)-\varphi(\hat{u})$ is defined and bounded $\mathcal{H}_{1}$-a.a. in $Q_{T}$ by its $L^{\infty}\left(Q_{T}\right)$ norm, the increasing of $\varphi(\cdot)$ implies that

$\lim _{\eta \rightarrow 0^{+}} H_{\eta}(w)=\operatorname{sgn}^{+}(\varphi(u)-\varphi(\hat{u}))=\operatorname{sgn}^{+}(u-\hat{u}), \mathcal{H}_{1}$-a.a.,$\left(\operatorname{sgn}^{+} \in B V(\mathbb{R})\right)$.

By the boundedness of $H_{\eta}(w)$ it is possible to apply the Theorem of Lebesgue, since $(u-\hat{u})_{t}$ is bounded.

Then,

$$
\begin{array}{r}
\lim _{\eta \rightarrow 0^{+}} \int_{Q_{t}} \rho(t) H_{\eta}(w)(u-\hat{u})_{t}=\int_{Q_{t}} \rho(t)\left(\operatorname{sgn}^{+}(u-\hat{u})\right)(u-\hat{u})_{t} \\
=\int_{Q_{t}} \rho(t)\left((u-\hat{u})^{+}\right)_{t}
\end{array}
$$

(see Corollary 3.3 in [11], sgn $^{+}$is a bounded Borel function).

Going to the limit as $\eta \rightarrow 0^{+}$in (108), we have

$$
\int_{Q_{t}} \rho(t)\left((u-\hat{u})^{+}\right)_{t} \leq 0
$$

that implies the nonincreasing of $(u(x, \cdot)-\hat{u}(x, \cdot))^{+}$as function of $t$. Hence,

$$
\int_{-L}^{0}(u(x, t)-\hat{u}(x, t))^{+} d x \leq \int_{-L}^{0}\left(u_{0}(x)-\hat{u}_{0}(x)\right)^{+} d x, \quad \forall t>0
$$

and the application $u_{0} \rightarrow u(\cdot, t)$ is a $T$-contraction in $L^{1}(-L, 0)$. For $u_{0}=\hat{u}_{0}$ in $[-L, 0]$ the uniqueness of solution follows. Thus, the choice of $\bar{u}$ becomes no more important.

At last, the following result holds 
Theorem 13. If $\left(H_{\varphi}\right)-\left(H_{\nu}\right),(76)$ and (103) hold, the problem (1)(4) has a unique strong solution. Moreover, (114) holds for any $t>0$ and gives an order preserving for the solution.

\section{References}

1. BÉnilan PH. AND TouRÉ H., Sur l'equation générale $u_{t}=\varphi(u)_{x x}-\psi(u)_{x}+v$, C. R. Acad. Sc. Paris 299, Serie I, no. 18 (1984), 919-922.

2. Betbeder J. B. and Vallet G., La question de l'unicité pour une classe de problèmes d'évolution non linéaires intégro-differentiels, $C$. R. Acad. Sc. Paris 317, Serie I (1993), 319-322.

3. Chavent G., "A New Formulation of Diphasic Incompressible Flow in Porous Media," Proceedings of IMU-IUTAM Symposium, Lecture Notes in Math. 503, Springer-Verlag, 1976, pp. 258-270.

4. Federer H., "Geometric Measure Theory," Die Grundlehren der Math. Wiss. 153, Springer-Verlag, Berlin, 1969.

5. Gagneux G., Une approche analytique nouvelle des modeles de la récuperation secondee en ingenierie petrolière, J. Mecan. Theorique et Appl. 5, no. 1 (1986), 3-20.

6. Gagneux G. and Madaune-Tort M., Sur la question de l'unicité pour des inéquations des milieux poreux, C. R. Acad. Sci. Paris, Serie I 314 (1992), 605-608.

7. Jingxue Y., On the uniqueness and stability of $B V$ solutions for nonlinear diffusion equations, Comm. Part. Diff. Eqns. 15(12) (1990), 1671-1683.

8. Lions J. L. AND Magenes E., "Problemes aux limites non homogenes et applications," vol. 1, Dunod, Paris, 1968.

9. Marcus M. and Mizel V. J., Absolute continuity on tracks and mappings of Sobolev spaces, Arch. Rational Mech. Anal. (1972), 294-320.

10. Madaune-Tort M., Un résultat de perturbations singulières pour des inéquations variationnelles degénérées, Ann. di Mat. Pura $e$ Appl., Serie IV CXXXI (1982), 117-143.

11. VAllet G., Sur des problèmes non linéaires provenant des transferts thermiques dans des systèmes disperses aubissants des changements de phases, Thèse, Pau, 1993.

12. VOL'PERT A. I., The spaces $B V$ and quasilinear equations, Math. USSR-Sbornik 2, no. 2 (1967), 225-267. 
13. Vol'Pert A. I. AND Hudjaev S. I., Cauchy's problem for degenerate second order quasilinear parabolic equations, Math. USSR-Sbornik 7, no. 3 (1969), 365-387.

Dipartimento di Matematica "G. Castelnuovo"

Universita' di Roma "La Sapienza"

00185 Roma

ITALY

Rebut el 17 de Gener de 1994 